\title{
Spectral detection of thalassemia: a preliminary study
}

\author{
M S AlSalhi ${ }^{1}$, Farjah H AlGahtani ${ }^{2}$, S Devanesan ${ }^{3,4}$, V Trinka Vijmasi ${ }^{5}$, K Jeyaprakash $^{6}$, Abbas H AlSaeed ${ }^{7}$ \\ and $\mathrm{V}$ Masilamani ${ }^{{ }^{*}}$
}

\begin{abstract}
Background: Thalassemias (Thal) are forms of inherited autosomal recessive blood disorders arising out of mutations in the chromosomes 11 or 16. These disorders lead to poor oxygen delivery to blood vessels and consequent splenomegaly, bone deformities, and shorter life spans. The most common detection methods for Thal are complete blood count (CBC) followed by electrophoresis and molecular diagnosis methods, such as high-performance liquid chromatography (HPLC) and polymerase chain reaction (PCR) genotyping. These methods involve sophisticated instrumentations and are cumbersome and expensive.

Results: In this study an innovative spectral detection method, based on the fluorescence spectra of a set of biomolecules (tyrosine, tryptophan, nicotinamide adenine dinucleotide, and flavin adenine dinucleotide and porphyrins) found in blood components is presented. An algorithm based on the spectral features of such biomolecules of blood components of 20 Thal patients (10 female and 10 male) and 18 age adjusted normal controls (4 female and 14 male) demonstrate reasonable level of classification with sensitivity and specificity values exceeding $90 \%$.
\end{abstract}

Conclusion: This new technique could be of significant value for Thal detection, diagnosis, and subsequent genetic counselling and could be adapted for use in small primary health centres.

Keywords: Blood plasma, Synchronous fluorescence excitation spectra, red blood cells (RBC), receiver operator curve (ROC), Thalassemia

\section{Background}

Thalassemias (Thal) are inherited autosomal recessive blood disorders caused by $\alpha$ or $\beta$ globin chain imbalances. Both imbalances lead to abnormal haemoglobin molecules that cause anaemia, which is a characteristic symptom of Thal. Most cases of $\alpha$ Thal are detected during new-borns screenings, but $\beta$ Thal is not apparent until the patients are 4-6 months old.

The $\alpha$ globin chain is encoded by four genes, one or more of which can be mutated or missing. The affected genes cause different levels of symptoms. For example, when only one gene is abnormal, the child is a silent $\alpha$ Thal carrier. A patient with two missing or mutated genes is described as $\alpha$ Thal minor or as having the Thal $\alpha$ trait. Patients with three mutated Thal genes have

\footnotetext{
* Correspondence: masila123@gmail.com

'Department of Physics and Astronomy, College of Science, King Saud University, P. Box: 2455, Riyadh 11451, Kingdom of Saudi Arabia Full list of author information is available at the end of the article
}

haemoglobin $\mathrm{H}$ disease, and those with four missing or mutated genes have a condition known as $\alpha$ Thal major or hydrops fetalis [1].

The $\beta$ Thal is caused by mutations in the genes that code for the $\beta$ globin chain. Three forms are well known: Thal minor, Thal intermedia, and Thal major. Individuals with $\beta$ Thal major usually present with severe anaemia within the first 2 years of life, poor growth, and skeletal abnormalities during infancy. Affected children require regular blood transfusions throughout their lives. The $\beta$ Thal intermedia are less severe than $\beta$ Thal major and therefore might require less frequent blood transfusions. Transfusion-dependent patients develop iron overloads and require chelation therapy to remove the excess iron. Bone marrow transplants can be curative for some children with $\beta$ Thal major.

Thal is carried by 150 million people, representing 3\% of the world's population, and is clinically apparent in 15 million people. It is particularly associated with people 
of Mediterranean, Arab, and Asian origins. Certain types of Thal are more common in specific parts of the world. $\alpha$ Thal is common in parts of the world where malaria is or had previously been endemic. $\beta$ Thal is much more common in Mediterranean countries, such as Greece, Italy, and Spain. Many Mediterranean islands, including Cyprus, Sardinia, and Malta, have significantly high incidence rates of severe $\beta$ Thal, constituting a major public health problem. For example, in Cyprus, 1 in 7 individuals carry the gene, which translates to 1 in 49 marriages between carriers and 1 in 158 new born who are expected to have $\beta$ Thal major [2].

On the other hand, $\alpha$ Thal is more common in Southeast Asia, India, the Middle East, and Africa. The carrier rates for $\alpha$ Thal are 1 in 7 for Cypriots, 1 in 12 for Greeks, 1 in 12 for Indians and 1 in 25 for Pakistanis. Thal is also common in the Kingdom of Saudi Arabia, particularly in the eastern and southern provinces. Premarital screening and genetic counselling centres associated with the Saudi Arabian Ministry of Health have reported a Thal prevalence rate of 18.5 cases per 1000 citizens (18 carriers and 0.5 with serious level of disease) [3].

Currently, many methods are being used to screen and diagnose Thal. The osmotic fragility test is commonly used for Thal screening, despite its low specificity. The most specific Thal diagnosis methods are haemoglobin (Hb) electrophoresis phenotyping [4] or high-performance liquid chromatography (HPLC) [5]. Other commonly used methods include polymerase chain reaction (PCR) and enzyme- linked immuno sorbent assay (ELISA) [6].

However, these techniques are expensive and cannot be used as routine laboratory tests in small hospitals or clinics. In this context, the present study describes the potential application of a spectral technique as a simple, inexpensive, and fast diagnostic protocol that could be employed in primary health centres in the Asian, Arabian, and African countries (which have highest prevalence of Thal).

The objective of the present study is to demonstrate the potential of spectral haemoglobinopathic diagnosis using well-defined Thal cases as examples. The spectra of blood cellular components and extracellular plasma could provide substantial insight into the subjects' pathologies.

\section{Methods}

Experiments were performed on blood plasma and red blood cell (RBC) samples from Thal patients and ageadjusted healthy controls.

Exactly $5 \mathrm{ml}$ of venous blood from 18 healthy volunteers (age range: 17 to 32 years) were collected in violet sterile vials that contained the anticoagulant EDTA. The vials were gently rocked five times to adequately mix the EDTA with the whole blood, and the samples were centrifuged at 3000 rotational speed (rpm) for 15 minutes. Clear, pale, greenish-yellow plasma supernatants were obtained by such centrifugation. A total of $1.5 \mathrm{ml}$ of supernatant was removed from the top layer for spectrofluorimetric analysis, leaving the buffy coat, the formed elements, and the undisturbed sediment. The blood plasma samples were subjected to synchronous fluorescence excitation spectral analyses without any other treatment.

Next, the buffy coats, which contained mostly white blood cells (WBCs) (e.g., lymphocytes), were removed and discarded, and exactly $1 \mathrm{ml}$ of the thick formed elements from the bottom layer, which contained mostly RBCs, was removed to a sterile vial and mixed with $2 \mathrm{ml}$ of analytical grade acetone. Proper care was taken to ensure that the formed elements did not develop lumps. After thorough mixing to enable the acetone to extract fluorophores within and around the cells, the samples were centrifuged again (3000 rpm for 15 minutes). The resulting supernatant was subjected to fluorescence emission spectra analysis at an excitation wavelength of $400 \mathrm{~nm}$.

The same protocol was used to process blood samples from confirmed Thal patients ( $\alpha$ and $\beta$ major) obtained from King Khalid University Hospital, Riyadh, Saudi Arabia from where the Institutional Review Board (IRB) approval had been obtained (approval number 12/3594/IRB). The patients were informed about the investigation, and proper consent was obtained. The Thal subjects consisted of 20 Thal patients (10 female and 10 male) with a median age of 25 years (range: $17-32$ years). The age and sex adjusted normal controls $(\mathrm{N}=18)$ were students, researchers, and staff nurses from whom informed consents obtained.

The following side line observations were noteworthy: The ratio between the plasma and cellular component volumes in normal patient samples was approximately $1.2: 1$, while the same ratio in Thal patient samples was nearly 1.8:1. Control plasma was greenish- yellow in colour, while patient plasma was yellowish in colour.

\section{Instrumentation}

The instrument used was a spectrofluorometer (PerkinElmer Luminescence LS 55) capable of collecting excitation, emission, and synchronous spectra in the $200-800 \mathrm{~nm}$ range. An excitation and emission slit width of $10 \mathrm{~nm}$ and scan speeds of $1000 \mathrm{~nm} / \mathrm{min}$ were used. The samples were placed in quartz cuvettes and illuminated by a specified wavelength of light with a $10-\mathrm{nm}$ spectral width and a spot size of $3 \times 2 \mathrm{~mm}$. The power at the point of illumination was approximately $20 \mu \mathrm{W}$, which was too low to induce photo bleaching. This finding was confirmed by repeating the experiment three times for each sample and observing no inter-replicate spectral differences.

Three types of spectra are measured in the field of fluorescence spectroscopy. In fluorescence emission spectra (FES), one particular wavelength is selected for the excitation of a molecule, and the fluorescence emission spectrum 
is obtained by rotating the emission grating over a predetermined range. The reverse is true of fluorescence excitation spectra (FXS), in which the peak emission band of a molecule is selected, and the excitation grating is rotated to scan the excitation spectra. In synchronous excitation spectra (SXS), both gratings are synchronously rotated at offsets of $40 \mathrm{~nm}$ or $70 \mathrm{~nm}$ to obtain the fluorescence excitation bands for every molecule in the predetermined range. The wavelength offset and scan range are not unique; they are determined empirically by trial and error, for a given set of experimental protocol. After analysing other offsets, including $10 \mathrm{~nm}$ and $30 \mathrm{~nm}$, it was determined that the $70 \mathrm{~nm}$ offset provided excellent resolution and good contrast between the normal and Thal samples because $70 \mathrm{~nm}$ is the Stokes shift $[7,8]$ of the most important biofluorophores (e.g., tryptophan) in blood plasma. Hence, all the results presented for plasma were based on the synchronous excitation spectra (SXS).

\section{Results}

Figure 1 shows the FES of the acetone extracts of blood cellular components from normal (a) and Thal samples (b), both of which were excited at $400 \mathrm{~nm}$. Both had peaks at $470 \mathrm{~nm}$, mostly due to the Raman acetone band in which the fluorescent bio molecules were suspended; the two additional bands at $580 \mathrm{~nm}$ and $630 \mathrm{~nm}$ represented the basic and neutral forms of porphyrin, respectively. By calculating the ratio $\mathrm{R}_{1}=\mathrm{I}_{630} / \mathrm{I}_{580}$, which was the intensity ratio between the bands at 630 and at $580 \mathrm{~nm}$, we obtained a value of approximately 1.2 for the normal samples and 0.5 for the Thal samples. The ratio values for these two sets are shown in Figure 2 and indicate a clear difference between the groups.
Figure 3(a) shows a typical synchronous excitation spectrum (SXS) of plasma of an age-adjusted normal control, a 25 year old female. The spectrum has three main peaks at $290 \mathrm{~nm}, 370 \mathrm{~nm}$, and $450 \mathrm{~nm}$. Of these, the $290 \mathrm{~nm}$ peak corresponded to the excitation peak of the amino acid tryptophan, the $370 \mathrm{~nm}$ peak corresponded to that of the coenzyme nicotinamide adenine dinucleotide (NADH), and the $450 \mathrm{~nm}$ peak corresponded to that of the metabolite flavin adenine dinucleotide (FAD). A shoulder was apparent at $275 \mathrm{~nm}$ on the shorter wavelength side of the $290 \mathrm{~nm}$ peak due to the amino acid tyrosine. The intensities of these peaks (in arbitrary units) were 225 for the $290 \mathrm{~nm}$ band, 70 for the $370 \mathrm{~nm}$ band, 40 for the $450 \mathrm{~nm}$ band, and approximately 160 for the $275 \mathrm{~nm}$ shoulder.

In contrast, a typical synchronous excitation spectrum (SXS) of plasma of a Thal patient (female, age 25) is shown in Figure 3(b). There were two major differences between the normal and Thal patient samples. The first difference was that the peaks were conspicuously out of proportion. The second was that the overall intensities were significantly lower in the Thal patients than in the normal controls. For example, the relative intensity ratio $R_{2}=I_{290} / I_{370}$ (which was the ratio of the peak intensities due to tryptophan and NADH) for the normal control was 2.4, while for the Thal patient value was 8.7. The two fluorescent biomarkers, tryptophan and NADH, were out of proportion in Thal patients, as indicated by the approximately 3.6 fold higher $R_{2}$ value for Thal patients. The scatter plot for $R_{2}$, shown in Figure 4, classifies the two sets quite well.

Similarly, $\mathrm{R}_{3}$, which was defined as $\mathrm{I}_{450} / \mathrm{I}_{370}$, or the ratio of the peak intensities at $450 \mathrm{~nm}$ and $370 \mathrm{~nm}$ due to

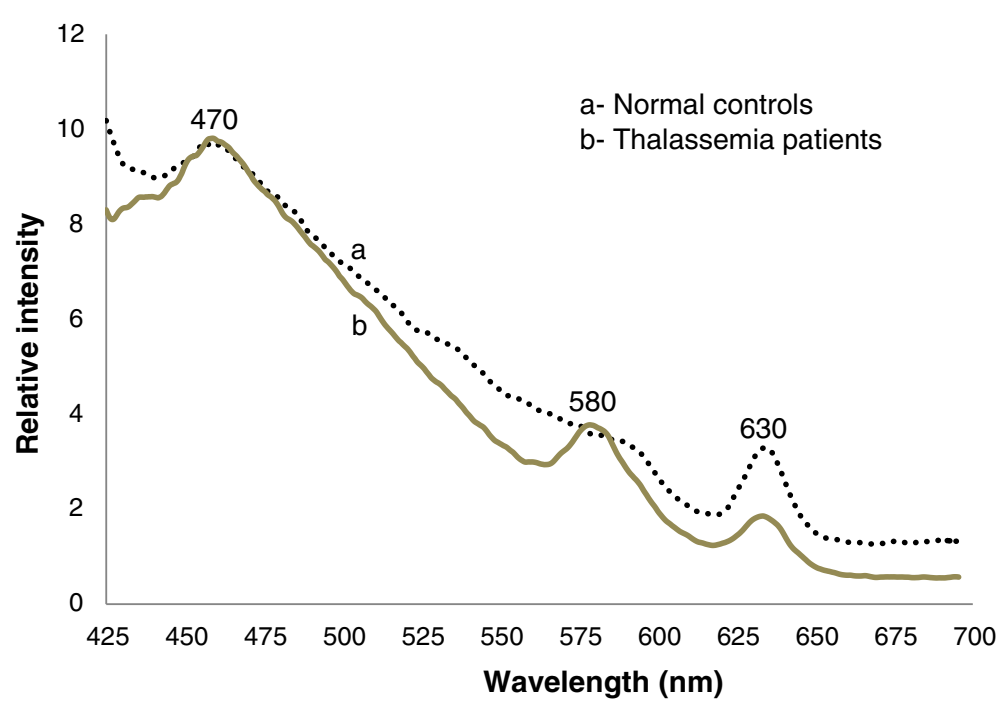

Figure 1 Fluorescence emission spectra (FES) of RBC acetone extract (excitation at $400 \mathrm{~nm}$ ). a- Normal controls. b- Thalassemia patients. 


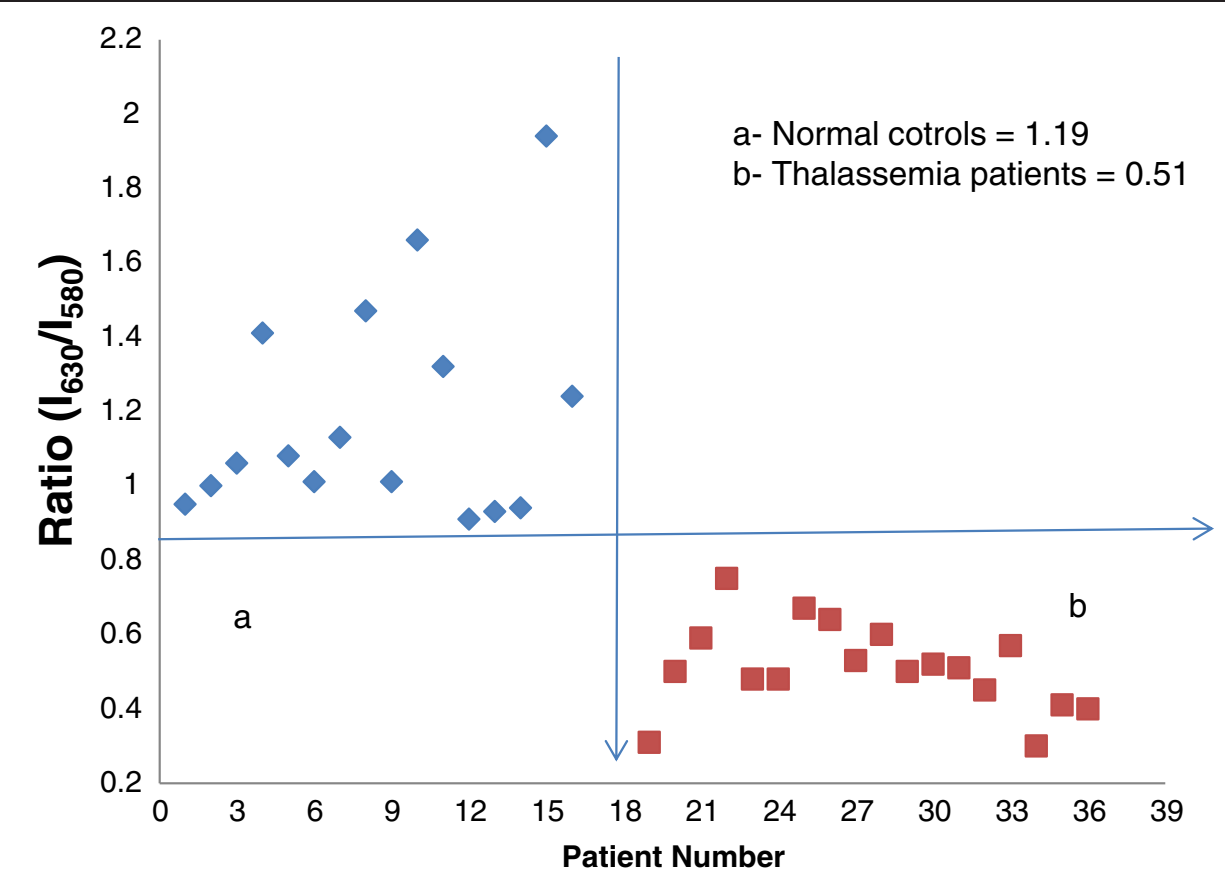

Figure 2 Distribution of $R=I_{630} / I_{580}$ ratios, as obtained from Figure 1. a- Normal controls $\mathbf{b}$ - Thalassemia patients.

FAD and NADH, respectively, was out of proportion in the Thal patients (Figure 3). We found that the mean of $R_{3}$ is 0.86 for the controls and 19.7 for the Thal patients. Using this classification method, it was possible to achieve specificity and sensitivity rates exceeding $96 \%$ because the FAD levels were abnormally high in Thal patients. See Figure 5.

Another unique feature was the relative peak elevation at $275 \mathrm{~nm}$ compared with that at $290 \mathrm{~nm}$ in the Thal patients, as shown in Figure 3. The normal control samples had a clear distinct band in the UV region at $290 \mathrm{~nm}$ with a weak shoulder at $275 \mathrm{~nm}$, but the reverse was true for the Thal patient samples. The $\mathrm{R}_{4}$ ratio of $\mathrm{I}_{275} / \mathrm{I}_{290}$ was approximately 0.8 for the normal samples but was increased to 0.9-2.1 (average: 1.39) for the Thal samples, as shown in Figure 6. Thus, the peak at $275 \mathrm{~nm}$ (due to tyrosine) was elevated 1.5 times in Thal patients.

Because the present study was limited to 38 samples (20 Thal and 18 control) only a simple, basic statistical analysis was performed; the means and standard deviations for

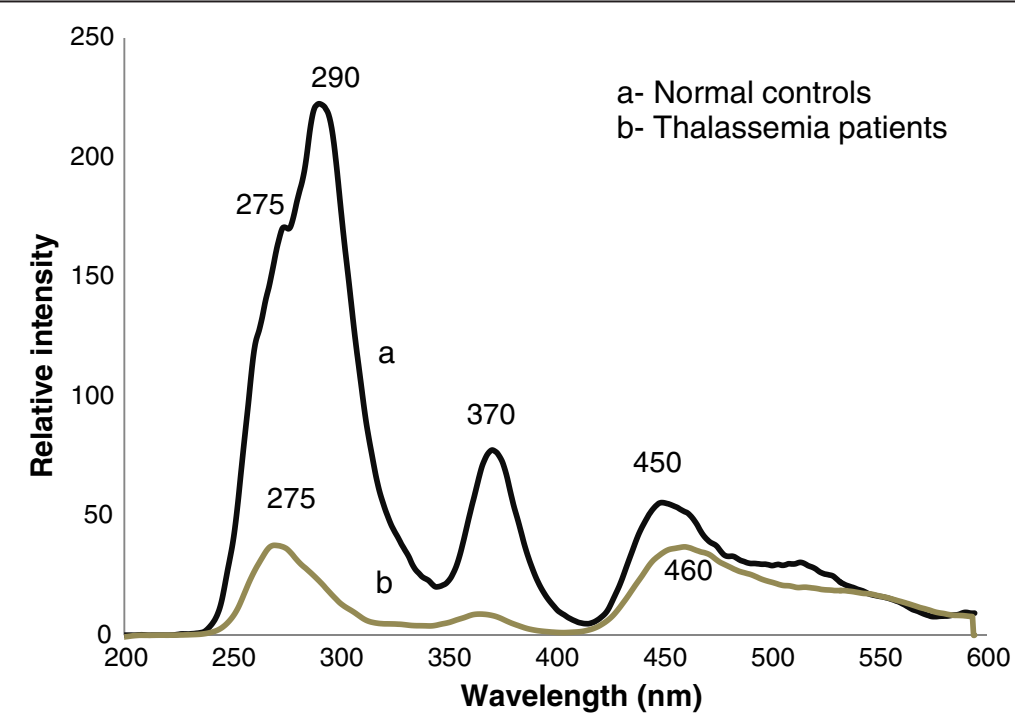

Figure 3 Synchronous excitation spectra (SXS) of plasma. a- Normal controls $\mathbf{b}$ - Thalassemia patients. 


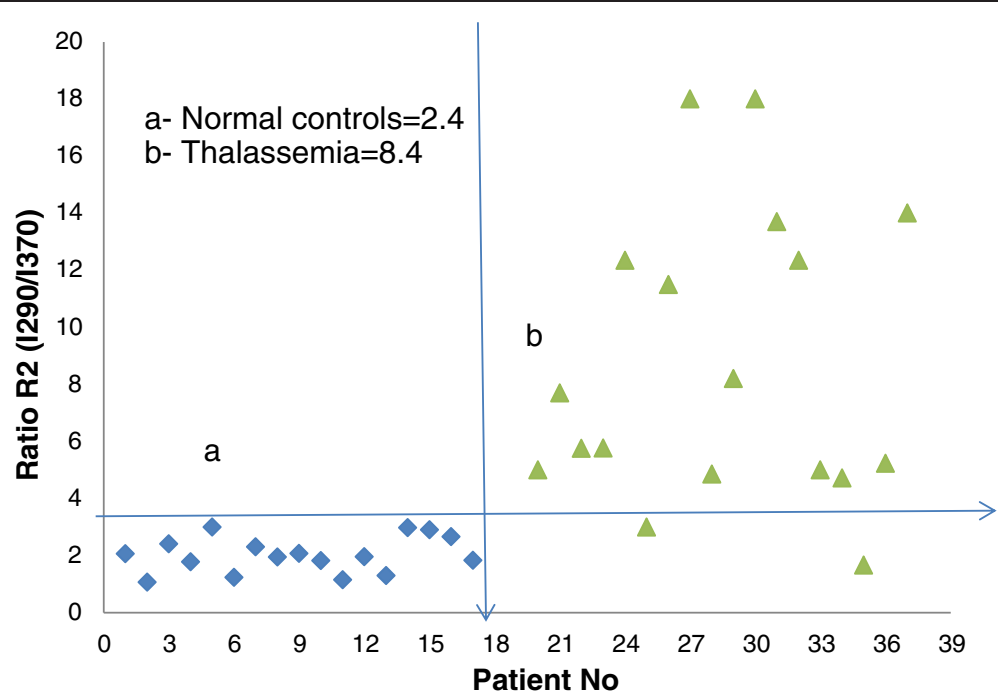

Figure 4 Distribution of $R_{2}=I_{290} / I_{370}$ ratios, as obtained from Figure 3. a- Normal controls $\mathbf{b}$ - Thalassemia patients.

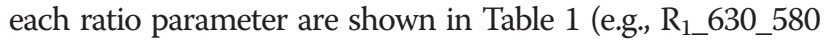
is the ratio of the intensities at 630 and $580 \mathrm{~nm}$ ). For each ratio, ID 1 indicates a normal sample, and 2 indicate a Thal patient sample; only one parameter, $\mathrm{I}_{290}$, was based on the absolute rather than the relative sample intensity. The $\mathrm{p}$-value for the two-tailed test was (less than 0.05 ) indicating good data separation. From these data, an ROC curve was drawn for the five ratio parameters. Figure 7 shows the ROC for $R_{1}$, which was obtained from the FES of acetone extract of RBC, and the absolute intensity parameter at $290 \mathrm{~nm}$ for the plasma. Figure 8 shows the ROC for other three plasma ratio parameters.
It is to be noted that, the ROC for the $R_{1}$, the runs along the two axes, indicating that this parameter is capable of classifying the samples with sensitivity and specificity levels of $100 \%$ each. The next best parameter is the $R_{3}$ (ratio of the $450 \mathrm{~nm}$ and $370 \mathrm{~nm}$ intensities), which has sensitivity and specificity levels of $94 \%$ each (Table 2).

\section{Discussion}

Thalassemias are blood disorders that lead to many complications, including fatigue, bone deformities, shortness of breath, growth failure, splenomegaly, and decreased life span. In developing countries, such as India and Pakistan,

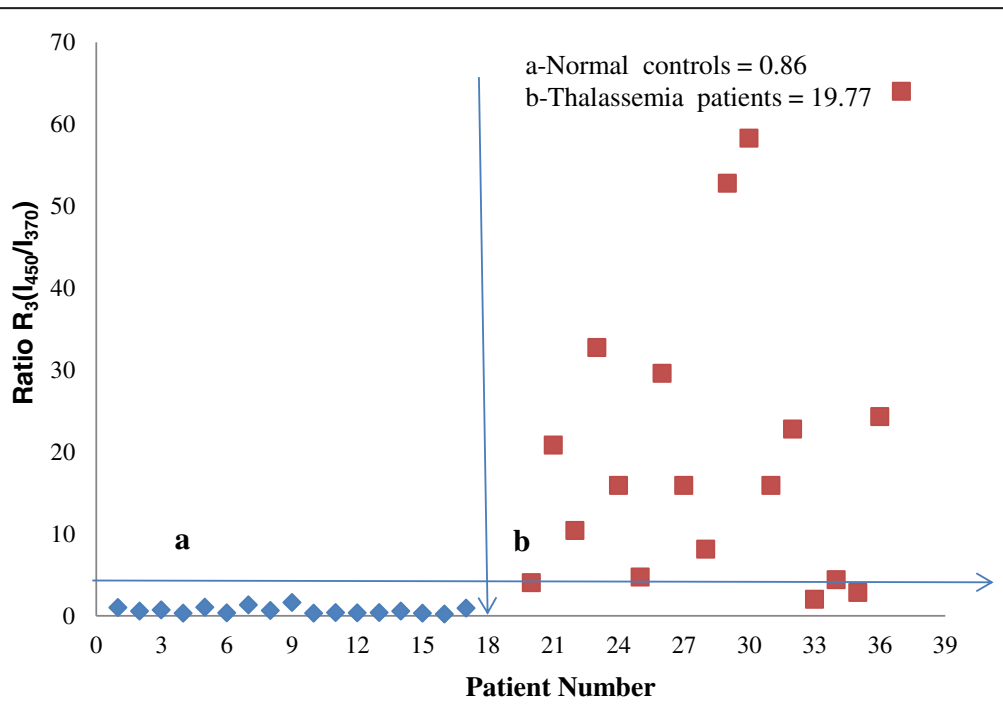

Figure 5 Distribution of $R_{3}=I_{450} / I_{370}$ ratios, as obtained from Figure 3. a- Normal controls $\mathbf{b}$ - Thalassemia patients. 


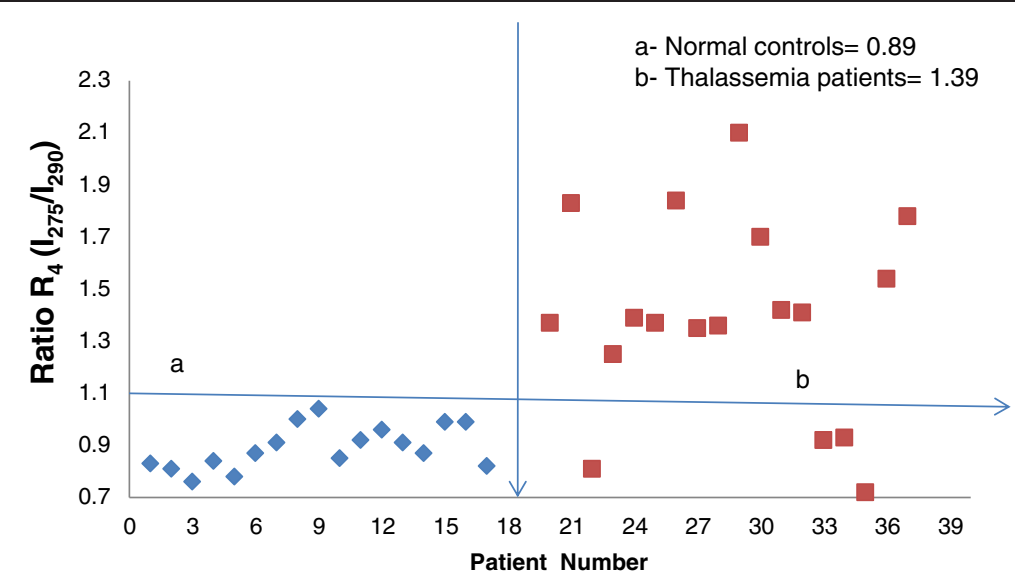

Figure 6 Distribution of $R_{4}=I_{275} / I_{290}$ ratios, as obtained from Figure 3. a- Normal controls $b$ - Thalassemia patients.

there are no organised programs for carrier screening or scientific counselling. In this context, the results of this study indicate that a simple spectrofluorimetric detection method could offer new prospects for inexpensive Thal detection.

A set of fluorescent blood biomarkers has been identified and quantified in Thal patients by employing synchronous excitation and fluorescence emission spectra. These spectra were compared to those of age -adjusted normal controls. The two sets showed distinctly different spectral features.

A spectral feature of cellular components is considered first.

We always measured the relative peak intensity at $630 \mathrm{~nm}$ (neutral porphyrin) with respect to the peak at $580 \mathrm{~nm}$ (basic porphyrin) as an internal reference. This ratio is dependent only on the molecules present in the sample and not on instrument factors, and it has been used extensively to detect cancer. In cancer patients, this ratio is approximately 3 or higher, while in normal controls, it is approximately 1 . Thus, malignancy generally increases this ratio 3 fold $[9,10]$. In contrast, this ratio in
Thal patients is approximately $50 \%$ of the control ratio. It is well known that the $\mathrm{RBC}$ content is significantly lower in Thal patients than in normal controls. In fact, the RBC content is the first test and classification factor for Thal. For all Thal cases in the present study, the RBC contents varied from 2 to 3.5 million $/ \mu \mathrm{L}$, with a mean value of 3 million $/ \mu \mathrm{L}$. In contrast, the $\mathrm{RBC}$ values for the normal controls, varied from 4.5 to 5.75 million $/ \mu \mathrm{L}$, with a mean value of 5 million $/ \mu \mathrm{L}$. This difference was reflected in our spectral analysis, shown in Figure 1 which is the fluorescence spectra of the cellular component acetone extracts. These findings provide direct spectroscopic evidence of the reduced RBC counts in Thal patients. As expected, we obtained a one to one correlation between the microscopic cell counts and the spectroscopic molecular diagnoses (Figures 1 and 2).

However, it was surprising to observe the effects of defective haemoglobin on the fluorescent plasma biomarkers (tyrosine, tryptophan $\mathrm{NADH}$, and FAD), as shown in Figure 2 to Figure 6. Of these biomarkers, the first two are well known essential amino acids, NADH

Table 1 Group statistics and independent 2-tailed $t$-test

\begin{tabular}{|c|c|c|c|c|c|c|}
\hline Parameter & ID & $\mathbf{N}$ & Mean & Std. deviation & Std. error mean & 2-tailed significance (P-value) \\
\hline \multirow[t]{2}{*}{ PK_290 } & 1.00 & 18 & 144.4833 & 88.16186 & 20.77995 & \\
\hline & 2.00 & 20 & 24.0410 & 29.91528 & 6.68926 & 0.05 \\
\hline \multirow[t]{2}{*}{ R1_630_580 } & 1.00 & 16 & 1.1913 & 0.29768 & 0.07442 & \\
\hline & 2.00 & 18 & 0.5117 & 0.11643 & 0.02744 & 0.06 \\
\hline \multirow[t]{2}{*}{ R2_290_370 } & 1.00 & 18 & 2.4106 & 1.15647 & 0.27258 & \\
\hline & 2.00 & 20 & 8.7770 & 6.26392 & 1.40065 & 0.08 \\
\hline \multirow[t]{2}{*}{ R3_450_370 } & 1.00 & 18 & 0.8678 & 0.99778 & 0.23518 & \\
\hline & 2.00 & 20 & 19.7755 & 19.16323 & 4.28503 & 0.03 \\
\hline \multirow[t]{2}{*}{ R4_275_290 } & 1.00 & 18 & 0.8994 & 0.10707 & 0.02524 & \\
\hline & 2.00 & 20 & 1.3465 & 0.39160 & 0.08756 & 0.002 \\
\hline
\end{tabular}




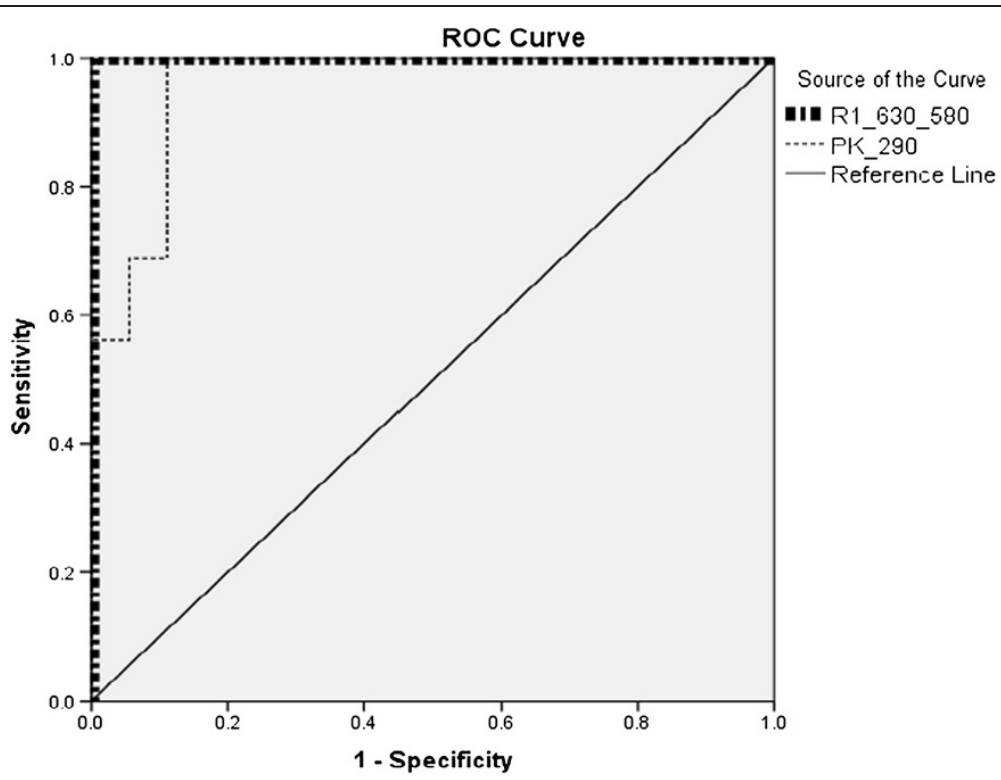

Figure 7 Receiver operator curve (ROC) obtained from the statistical evaluation of the data for $\mathrm{R}_{\mathbf{1}}$ and the absolute intensity at $290 \mathrm{~nm}$. Note that, for $R_{1}$, the curves run parallel to the $X$ and $Y$ axes.

is a coenzyme, and FAD is a metabolite that is involved in many cellular redox activities. All these molecules are misregulated in Thal and cancer patients [8].

The most striking observation was the abnormal elevation in FAD levels (SXS at $450 \mathrm{~nm}$ ) and the equally abnormal decrease in NADH levels (SXS at $370 \mathrm{~nm}$ ); the ratio between these two biomarkers provided a diagnostic accuracy of $94 \%$. There could be many reasons for these aberrations. For example, RBCs decays at a much faster rate in Thal patients than in normal controls due to the faulty globins, and FAD is a well-known metabolite that is involved in all cellular redox activities. In the decay of one $\mathrm{RBC}$, two NADH molecules are involved, which could be the main reason for the abnormal decrease in NADH levels. Another possible reason is that NADH might transfer a significant amount of excitation energy to FAD due to the strong overlap of the NADH emission band and the FAD absorption band. Similar reductions in NADH levels

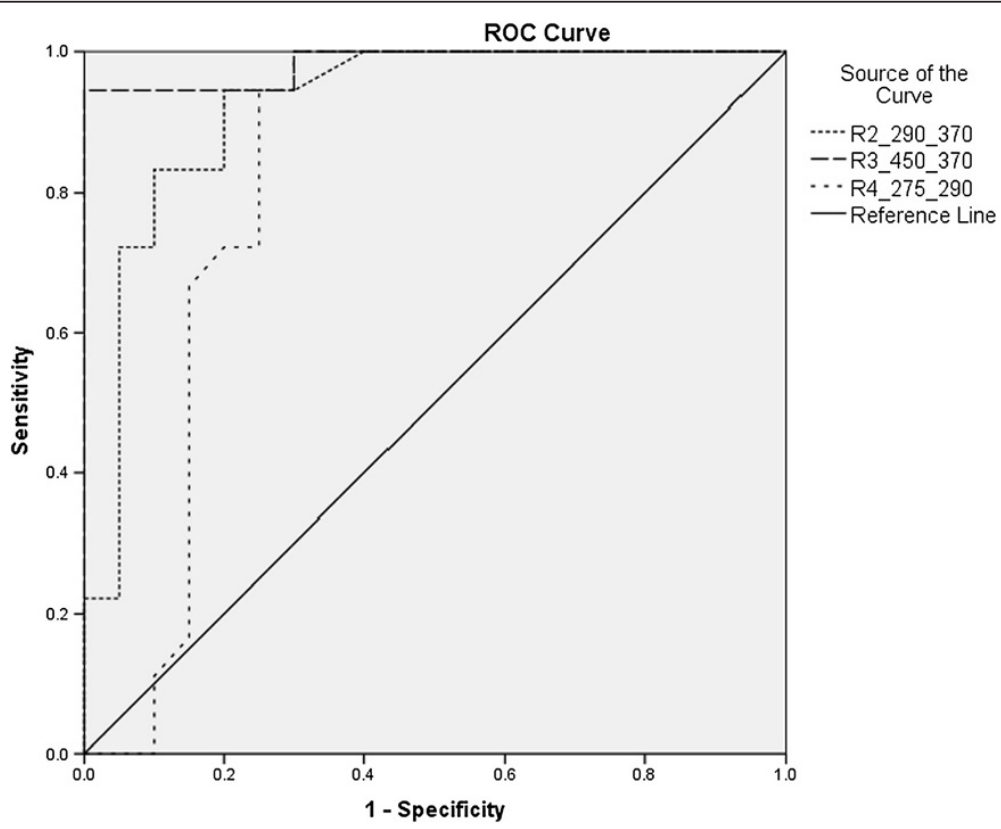

Figure 8 Receiver operator curve (ROC) for the other ratio parameters, obtained from the plasma SXS. 
Table 2 Sensitivity, specificity, and area under the curve

\begin{tabular}{lcccc}
\hline Test parameters & $\begin{array}{c}\text { Area under } \\
\text { the curve }\end{array}$ & $\begin{array}{c}\text { Cut-off value } \\
\text { (Threshold) }\end{array}$ & $\begin{array}{c}\text { Sensitivity } \\
\text { (\%) }\end{array}$ & $\begin{array}{c}\text { Specificity } \\
\text { (\%) }\end{array}$ \\
\hline R1_630_580 & 1.000 & 0.83 & 100 & 100 \\
R2_290_370 & 0.922 & 3.5 & 81.3 & 88.9 \\
R3_450_370 & 0.983 & 1.9 & 93.8 & 94.6 \\
R4_275_290 & 0.825 & 1.0 & 87.5 & 77.5 \\
PK@290 & 0.958 & 51 & 100 & 90 \\
\hline
\end{tabular}

and increases in FAD levels have been reported in blood and urine samples from patients with advanced and aggressive cancers, such as Hepatocellular carcinoma [8].

As shown in Figure 3, the first peak in normal plasma samples occurred at $290 \mathrm{~nm}$ with a shoulder at $275 \mathrm{~nm}$. These peaks were reversed in Thal patient plasma samples. The ratio $R_{3}=I_{275} / I_{290}$ was approximately 0.8 for control samples and 1.4 for patient samples. Tyrosine and tryptophan are closely related essential amino acids. In Thal patients, the low oxygen levels that are caused by abnormal haemoglobin might upset the equilibrium of these amino acids.

Some essential statistics were calculated for the classifications of the normal (set 1) and Thal diseased patients (set 2), employing independent ratio parameter. $R_{1}$ is the ratio of two types porphyrin concentrations found in cellular components; $R_{2}$ is the ratio for FAD/NADH concentration found in plasma; $R_{3}$ is the ratio for tyrosine/ tryptophan concentration found in plasma. For each one of them, specificity and sensitivity exceeded $90 \%$.

\section{Conclusion}

In this preliminary spectral investigation on fluorescent biomarkers in Thal blood samples involving a limited number $(\mathrm{N}=20)$ of known Thalassemia cases and ageadjusted normal controls $(\mathrm{N}=18)$, distinction between the two sample sets could be achieved with an accuracy that exceeded $90 \%$. This result is only indicative of the efficacy of spectral diagnosis. In the near future, we plan to conduct a large-scale field trial to distinguish between Thal major, minor, and intermedia, which will confer viable clinical value to this technique.

\section{Abbreviations}

Thal: Thalassemia; EDTA: Ethylene diamine tetra acetic acid; FES: Fluorescence emission spectra; FXS: Synchronous excitation spectra; NADH: Nicotinamide adenine dinucleotide; FAD: Flavin adenine dinucleotide.

\section{Competing interest}

The author's declare that they have no competing interest.

\section{Author's contributions}

VM, MSA, and SD, made substantial contributions to the analysis and interpretations of data; Drafting of the manuscript and also responsible for overall experiments. FHA and AHA provided the biological samples. VTV did statistical analysis. KJ helped improve the text. All authors read and approved the final manuscript.

\section{Acknowledgements}

The authors would like to extend their sincere appreciation to the Deanship of Scientific Research at King Saud University for its funding of this research through the Research Group Project No "RGP- VPP-223".

\section{Author details}

${ }^{1}$ Department of Physics and Astronomy, College of Science, King Saud University, P. Box: 2455, Riyadh 11451, Kingdom of Saudi Arabia.

${ }^{2}$ Department of Haematology, King Khalid University, Riyadh, Kingdom of Saudi Arabia. ${ }^{3}$ Research Chair, Laser Diagnosis of Cancers, King Saud University, Riyadh, Times New Roman. ${ }^{4}$ Research and Development Centre, Bharathiar University, Coimbatore, India. ${ }^{5}$ Proctor Foundation, University of California, San Francisco, CA, USA. ${ }^{6}$ PG and Research Department of Biochemistry, Rajah Serfoji, Govt College, Thanjavur, India. ${ }^{7}$ College of Medical Sciences, King Saud University, Riyadh, Kingdom of Saudi Arabia.

Received: 26 December 2013 Accepted: 24 March 2014

Published: 29 March 2014

\section{References}

1. World Bank, report of a joint WHO-March of Dime meeting. Published by Thalassemia international federation; 2006

2. World health organization (WHO): Fact sheet, sickle cell disease and other haemoglobin disorders; 2006. http://www.who.int/mediacentre/factsheets/ fs308/en/index.html.

3. Baker HA: Thalassemia syndromes in Saudi Arabia- Meta-analysis of local studies. Saudi Med J 2000, 21:8-17.

4. Fucharoen S, Winichagoon P, Piankijagum A: Standardization on laboratory diagnosis of thalassemia and abnormal haemoglobin. Southeast Asian J Trop Med Public Healh 1999, 30:90-98.

5. Colah RB, Surve R, Sawant P, Souza ED, Italia K, Phanasgaonkar S, Nadkarni $\mathrm{AH}$, Gorakshakar AC: HPLC studies in hemoglobinopathies. Indian J Paed 2007, 74:57-662.

6. Tatu T, Kiewkarnkha T, Khuntarak S, Khamrin S, Suwannasin S, Kasinrerk W: Screening for co-existence of a-thalassemia in $\beta$-thalassemia and in $\mathrm{HbE}$ heterozygotes via an enzyme-linked immunosorbent assay for $\mathrm{Hb}$ Bart's and embryonic Z-globin chain. Int J Hemat 2012, 95:386-393.

7. Alfano RR, Yang Y: Stokes shift emission spectroscopy of human tissue and key biomolecules. IEEE J Quantum Electron 2003, 9:148-153.

8. AlSalhi MS, AlMehmadi AM, Abdo AA, Prasad S, Masilamani V: Diagnosis of liver cancer and cirrhosis by the fluorescence spectra of blood and urine. Tech Can Res and Treat 2012, 11:345-351.

9. Masilamani V, AlZhrani K, AlSalhi MS, Al Diab A, Al Ageily M: Cancer diagnosis by autofluorescence of blood components. J Luminescence 2004, 109:143-154.

10. AlSalhi MS, Masilamani V, Trinka V, AlNachawati A, VijayaRaghavan AP: Lung cancer detection by native fluorescence spectra of body fluid- a preliminary study. J Fluorescence 2011, 21:637-645.

doi:10.1186/1423-0127-21-26

Cite this article as: AlSalhi et al: Spectral detection of thalassemia: a preliminary study. Journal of Biomedical Science 2014 21:26.

\section{Submit your next manuscript to BioMed Central and take full advantage of:}

- Convenient online submission

- Thorough peer review

- No space constraints or color figure charges

- Immediate publication on acceptance

- Inclusion in PubMed, CAS, Scopus and Google Scholar

- Research which is freely available for redistribution 